\title{
FLORA EUROPAEA IN VIENNA
}

$\mathrm{T}$ HE first full meeting of the Flora Europaea Organization was held in Vienna during April 1-7, 1959, at the Naturhistorisches Museum. The international gathering included botanists from Austria, Belgium, Denmark, Finland, France, Germany, Hungary, Iceland, Italy, Jugoslavia, Norway, Poland, Roumania, Sweden, Switzerland, Spain, as well as members of the British Editorial Committee. As editors, advisers and consultants of Flora Europaea they had come to discuss ways and means of consolidating the progress already made in the project and to debate the various theoretical and practical problems which have arisen so far.

The meeting, officially a 'round table symposium', was organized by the Editorial Committee, and the local arrangements were made with the assistance of a preparatory committee of Austrian botanists under the chairmanship of Dr. K. H. Rechinger, director of the Botanical Department of the Museum. The Austrian Ministry of Education contributed to the local expenses, and the International Union of Biological Sciences made a grant to assist members attending. Introductory addresses were given by Prof. H. Strouhal, director of the Museum, Dr. K. H. Rechinger, and the chairman of the Editorial Committee, Prof. T. G. Tutin (Leicester). Prof. Tutin recounted the history of the project, which originated as a result of discussions at the eighth International Botanical Congress held in Paris in 1954. He outlined the principles which had guided the Editorial Committee in its decisions on the size, limits and scope of the work. It was essentially an attempt to summate in one work the essence of taxonomic research made on European plants during the past two centuries, and provide a concise and modern Flora of Europe.

The main work of the meeting was divided into formal sessions in the mornings, during which papers were presented and discussed, and informal afternoon sessions, during which various practical problems were considered. These informal discussions contained much valuable material, which is being edited for inclusion with the main papers in the publication of the proceedings.

The first major topic dealt with was the taxonomy of apomicts. Prof. D. H. Valentine (Durham) gave a paper outlining ways in which the Committee suggested the different kinds of apomictic groups could be treated. It was difficult to lay down general principles for the treatment of all groups since our knowledge of them is so uneven. In dealing with Hieracium, Taraxacum, Rubus, Ranunculus auricomus, Potentilla, Alchemilla and Gramineae, he attempted to set the taxonomic problems against the background of our knowledge of the apomictic mechanisms and the evolutionary potentialities of the groups. Such an evolutionary approach, although not always of direct value, often helped the taxonomist to assess what could be attempted and how far ho could go. In Rubus, for example, new populations are being constantly produced by hybridization, whereas in most of the Alchemilla vulgaris group no hybridization is known. Both groups have been fairly thoroughly investigated by taxonomists, but these evolutionary facts should have a bearing on future attempts to produce workable taxonomic treatments. The problem for Flora Europaea was largely one of devising methods for eurtailing and limiting the accounts. Only widely distributed taxa should perhaps be described and endemic taxa dealt with briefly, if at all. All apomictic groups will be dealt with by normal taxonomic methods and will be placed in aggregate species, subspecies or, in exceptional cases, varieties. Experimental categories such as 'agamospecies' will not be used in the Flora, but reference to reproductive mechanisms and other relevant points may be made in the form of observations in the text. This paper was extensively discussed, and particular attention was directed to the procedure of Marklund in his treatment of Fennoscandian Ranunculus auricomus representatives, which he grouped into four aggregates which were differentiated morphologically, ecologically and geographically. It was the opinion of several speakers that a similar treatment could be applied to the whole of Europe.

Prof. B. Pawlowski (Cracow) gave the second paper. He made four principal points: $(a)$ for apomicts current taxonomic categories should be employed; (b) the degree of differentiation of apomicts varies from group to group; (c) the most appropriate method of treatment should be left to the author of a particular group to decide; and (d) extensive descriptions should be permitted as a departure from the normal abridged ones of Flora Europaea.

In the general discussion the point was made that the level of treatment possible in any apomictic group depended on a number of factors such as the kind of apomixis, the number of taxa likely to be involved, their stability, the treatments already published and how far they could be applied to Europe as a whole. Prof. R. Nordhagen (Oslo) suggested that the term vegetative apomixis was misleading and should be replaced. He believed that phylogenetic lines should be followed in the treatment of such groups as Taraxacum and Hieracium, but about Rubus he would not speak. Prof. H. Merxmüller (Munich) proposed that in the Ranunculus auricomus group not only the extreme forms ( $R$. auricomus and $R$. cassubicus) should be given, but also 'central' forms under which taxa not belonging to the corner forms could be accommodated. For Taraxacum he proposed as models the treatment given by Böcher, Holmen and Jakobsen in "Grønlands Flora" and van Soest's survey of the phytogeography of the genus. The sections recognized are more or less equivalent to aggregates. Keys to this level should be sufficient with further information on apomicts of special interest. For Hieracium a possible method wonld be to follow Janchen in regarding Zahn's Arten as aggregates and joining the Unterarten in greges, the keys not going farther than this level. The number of Zahn's Zwischenarten would have to be greatly reduced by the exclusion of primary hybrids. Prof. W. Rothmaler (Greifswald) stressed that apomixis is only one of numerous methods in the plant kingdom and that there was not in principle a basic difference between a persistent inbreeder and an apomict. Normal taxonomic methods should be applied to these groups. Dr. A. Löve (Montreal) considered it unfortunate that many taxonomists adhered to the dictum of Winge that the description of hundreds of so-called apomictic species was laying "too much stress on immaterial bagatelles", rather like the 
collecting of postage stamps. Recent biosystematic studies had shown that apomictic taxa may be of considerable geographical and evolutionary importance. A practical solution could be achieved by combining the system of Turesson (using special categories agamospecies, agamotype, apomict) and that of Marklund. Thus, if the term agamospecies is accepted for apomictic microspecies as approximately the same lovel as the subspecies proposed by Marklund (and at a lower level than proposed by Turesson) it could be incorporated into the taxonomic system as a category at the subspecific level. The inclusion of only agamospecies at subspecific level would automatically indicate that the species itself is agamospermous, while the inclusion of one or more subspecies also would show that sexual seed formation is also known to occur in the species. Dr. N. Hylander (Uppsala) felt that such a system would not be workable since it was not known in many cases to what extent a species was agamospermous, and therefore such terms as hemiagamospecies would have to be introduced.

The second set of papers dealt with problems of geographical distribution and taxonomy. Prof. $\mathrm{H}$. Meusel (Halle) read a paper outlining his system for indicating the distribution of species by means of formulæ. This system is based on three main elements -countries, floral elements and geographical coordination (floral zones, oceanity-continentality, and 'étages'), and together with distribution maps summarizes a great deal of information in a short space (see Meusel, H., "Arealformen und Florenelemente als Grundlagen einer vergleichenden Phytochorologie" in Forsch. und Fortschur., 33, 163 ; 1959). Meusel's scheme was greatly admired, and it was hoped that it could be extended to the whole of Europe, but it was felt that the limiting factor was the technical one of amassing and processing the data for thousands of species, especially from understudied floras, in time for inclusion in Flora Europaea. Moreover, the number of symbols involved was a serious drawback in a general Flora.

This provoked an illuminating debate about the source and reliability of data used in indicating extra-territorial distributions in Floras in general. The indication in a more or less summarized form of the total distributions of species is almost traditional in most Floras. Dr. V. H. Heywood (Liverpool, secretary of the Editorial Committee) doubted the validity of these data in most cases, since they wore almost invariably copied from the literature and errors were thereby perpetuated. Flora Europaea was not intended to be a handbook of plant geography. Prof. D. H. Valentine emphasized the difficulty of knowing whether the species were the same in the various countries from which they are recorded according to these total distributions. Dr. Heywood then talked on some of the problems of taxonomy and distribution in the West Mediterranean, especially the Iberian Peninsula, many parts of which are inadequately known from a floral point of view. This contrasted with taxonomically well-studied areas such as Scandinavia and Central Europe and created grave problems for the authors and editors of the Flora. One result of inadequate exploration in the Iberian Peninsula was that patterns of distribution were far from clear. Gaps may be due to incomplete knowledge and not to the fact that the species concerned show discontinuous areas. The concern here was with basic taxonomy, and there is virtually no cytological or experimental information available.
The treatment of three kinds of endemics was considered: endemic vicariant species such as Ptilotrichum reverchonii (S.E. Spain) and $P$. pyrenaicum (Pyrenees), where the temptation to unite them should be resisted despite their close morphological similarity; Wettsteinian subspecies showing good geographical pattern with areas of overlap; and micro-endemic vicariants. The latter kind has proved difficult to deal with satisfactorily and is typical of the Mediterranean mountain flora, where each range or peak may have its own endernic representative of a species. Populations have been fragmented into discrete units, but each one is only slightly different from the next, however constant the differences may be. Currently these units are regarded as varieties, subspecies or species, and some uniformity should be introduced to deal with this frequent phenomenon.

The species versus subspecies question was also considered by Dr. K. H. Rechinger in his paper on distributional problems in South-east Europe, where he considered dealing with 8,000 species in the Balkan Peninsula. Although there were many similarities between South-east and South-west Europe, there were a number of differences in climate, physiography, coastlines, etc., which altered the kind of problems found. In the east, one concerned the problems of the island floras with their endemic races, and many years experience had convinced him of the need for a fairly narrow species concept in polymorphic complexes until a detailed revision was possible. Prof. H. Merxmüller (Munich) spoke on the taxonomic treatment of Alpine vicariants, where again the species versus subspecies problem arose. Not all Alpine vicariants could be placed in either category but should be considered for such treatment whenever they showed satisfactory morphological separation coupled with geographical distribution. The important point was to be consistent in their treatment within a group. Too close an adherence, however, to the Wettstein geographical-subspecies method could lead to absurd results whereby species were divided into a series of boxes of little meaning.

The taxonomic treatment of polyploidy was the subject of another set of papers. Prof. W. Rothmaler in his discourse on "Taxonomy and Geneties" said that the working methods and principles of taxonomy must not be mixed with those of genetics. Each taxon corresponds to a concept the extent and importance of which is determined by taxonomic methods. In a species concept, all information, morphological, geographical, ecological and physiological, must be combined with genetical, anatomical and other evidence, but no one line of evidence should be given a greater level of importance than any other. Thus, as regards polyploidy, the chromosome status should be regarded as a valuable aid for the definition of a taxon but should not be given greater importance than any character of internal or external morphology. Similar considerations applied to apomicts. Chromosome numbers may vary as much within a species or subspecies, as they remain constant within a large genus or even part of a family. Dr. V. H. Heywood then gave a paper on "The Taxonomy of Polyploids in Flora Europaea", which was an attempt to suggest practical solutions for dealing with this kind of problem in the Flora. Ho agreed with Rothmaler's view that no one character or line of evidence is per se sufficient to indicate specific status. The bearing of polyploidy in an experimental or genetic special classification is quite different, he suggested, from its value in a taxonomic 
framework. He dealt with autoploid, alloploid and polyploid complexes, although agreeing that it was not always meaningful or even possible to distinguish between these situations. He proposed that 'cryptic' polyploids should receive no taxonomic recognition, although their existence, and if possible their distribution, should be noted in observations. 'Semicryptic' polyploids may be amenable to treatment as varieties, subspecies or in exceptional cases species. Distinct autoploids are undoubtedly rare and should receive specific rank only when they are constantly recognizable; otherwise, if intermediates are known and especially if their geographical areas overlap, they should be given subspecific or varietal rank. Taxa which have arisen by polyphyletic (polytopic) polyploidization should be considered grades sensu Huxley and treated as varieties or even forms. Dr. Hylander agreed almost entirely with these views, whereas Dr. A. Löve disagreed almost entirely and proceeded to elaborate his arguments in a paper, "Taxonomy and Chromosomes-a Reiteration". "He considered that Flora Europaea should be the beginning of a new era in European taxonomy, not the end of an old outdated epoch. The chromosomes are not just another character comparable to the superficial morphological characters which taxonomists are forced to use in the identification of herbarium material. They determine the characters, whereas the characters do not determine the chromosomes. Changes in the chromosomes determine the divergent evolution of ecotypes and races and then the effective isolation of species, genera and families. The only logical rule for the classification of taxa differing in chromosome number is to name them as distinct species. The ensuing discussion was lively. It was agreed that as much cytotaxonomic information as possible should be given in the Flora, although people were not entirely agreed on its taxonomic importance. A liberal use of species aggregates was a possible solution for morphologically similar (though not identical) cytotypes.

A botanical excursion was arranged by Dr. F. Ehrendorfer on the Monday to Burgenland and Neusiedlersee. The view of the Danube, the large lake and the fascinating salt steppes, combined with the rich spring flora to make it a memorable day. In the evening the participants were given a banquet by the local Government Council at Rust, at which Government Councillor Kunnert mentioned the cultural and scientific traditions of Burgenland-for example, here lived Haydn and the celebrated botanists Clusius and Kitaibel.

The final sessions dealt with the problems of cul. tivated, escaped and adventive plants. Dr. N. Hylander spoke on his experience with similar problems in the Scandinavian flora. Not only plants of natural habitats but also those growing in localities created or strongly influenced by man had to be considered. Similarly, some of the species growing wild were intentionally or unintentionally introduced by man. It was often impossible to distinguish clearly between these different types. Prof. J. Jalas (Helsinki) gave a paper on "Treatment of the Aliens in Flora Europaea". The alien element could be considered as belonging to the following groups : (1) naturalized or established aliens of extra-European origin ; (2) European species occurring in some parts of the area merely as $(a)$ naturalized or established aliens, or $(b)$ casual adventives. If thoroughly naturalized in one or more European countries the aliens should be described and keyed normally, irrespective of their degree of commonness. Taxa native only outside Europe should be marked with a special sign. The same sign should be used to indicate territories in which native European species are only naturalized. The territories within which a species, whether European or not, occurs as a casual should be enclosed in square brackets. In a second paper he illustrated the valuable data that can be obtained about variable species such as Medicago lupulina from countries near the outer limits of their permanent occurrence.

Mention must be made in conclusion of the generous hospitality of the Minister of Education and the Bürgermeister of Vienna, both of whom gave receptions for the participants. A meeting in Vienna would be scarcely complete without a visit to the Wienerwald, and this was also arranged by the city authorities, ending with a Heuriger at Heiligenstadt where, in true botanical tradition, the 'new' wine was liberally sampled. Altogether, the symposium was one of the most successful and certainly the most enjoyable which even Prof. Lüdi could remember.
V. H. HEYWOOD

\title{
EFFECT OF SOAP ON THE DIFFUSION OF WATER THROUGH ISOLATED HUMAN EPIDERMIS
}

\author{
By F. RAY BETTLEY and ELAINE DONOGHUE \\ Institute of Clinical Research, Middlesex Hospital, London
}

\begin{abstract}
$\mathrm{T}$ HERE is reason for supposing that soap and other detergents increase the permeability of the skin. Thus, Kvorning and Svendsen ${ }^{1}$ found that if I per cent 'Teepol' is incorporated with the test solution, patients sensitive to chromium and nickel react to a lower concentration than if chromium or nickel salts are used alone. Skoge found that pretreatment of the skin with soap or non-soap detergent led to a higher proportion of irritant reactions from dinitrochlorbenzol. Burckhardt ${ }^{3}$ pretreated the skin with soap and found that the damage so inflicted predisposed to the experimental development of
\end{abstract}

nickel sensitivity; but in his experiments gross damage was inflicted on the skin by the alkaline soap. This was perhaps more comparable with the increased sensitization to dinitrochlorbenzol obtained by Rockwell ${ }^{4}$ in skin which was prepared by sandpapering.

The barrier which prevents passage between the tissues and the outside has been much investigated and is reviewed by Rothman ${ }^{5}$. It lies between the corneous layer and the Malpighian layer and is not identifiable with histological precision. According to Rothman, it is an electric double layer with hydrogen 